\title{
DIAGNÓSTICO DE CONDOMÍNIOS DE ARMAZÉNS RURAIS NO OESTE BAIANO
}

\author{
Tomaz Sardeiro Grinaldo ${ }^{1}$; Amanda Cristina Gaban Filippi ${ }^{2}$; Patricia Guarnieri $^{3}$. \\ 1 - Administrador pela UnB. Universidade de Brasília (UnB). E-mail: grinalde@gmail.com. \\ 2 - Doutoranda em Agronegócios (UFG), Mestre em Agronegócios (UnB) e Engenheira Agrônoma \\ (ESALQ / USP). E-mail: amandagaban@hotmail.com. \\ 3 - Profa. Visitante na Università di Bologna, Departamento de Engenharia Industrial. Profa. do curso \\ de Administração da Universidade de Brasilia (UnB), Programa de Pós-Graduação em Agronegócio e \\ do Programa de Pós-Graduação em Administração da Universidade de Brasília (UnB). Doutora em \\ Engenharia de Produção (UFPE). E-mail: profpatriciaunb@gmail.com.
}

\section{Resumo}

O presente trabalho teve como propósito identificar a existência e perspectivas de Condomínios de Armazéns Rurais no Oeste Baiano, bem como a logística de distribuição, a qual esta inserida na nova fronteira agrícola no país, o MATOPIBA. Para atingir esse objetivo foi realizada uma pesquisa aplicada, exploratória, descritiva e de abordagem qualitativa, através de entrevista semiestruturada. A análise de dados se deu através da Análise de Conteúdo. Identificou-se que os agricultores locais participam de algumas formas de Associativismo, como Cooperativas e Associações. Foi encontrada ainda uma possível evidência da existência de Condomínio de Armazém Rural no Oeste Baiano, além de Cerealistas na região. Ademais, diante da produção local representativa e do déficit de armazenagem, há potencial para implantação dos Condomínios de Armazéns Rurais na região. Por ser um tema relativamente novo, os entrevistados pouco sabiam da ação coletiva e de suas características. Nesse contexto, esse trabalho contribuiu para a difusão do arcabouço teórico e de conhecimento sobre os Condomínios de Armazéns Rurais na região, e abre oportunidades de novas pesquisas sobre a ação coletiva.

Palavras-chave: Ações Coletivas Rurais; Logística; Desenvolvimento Rural. 


\title{
DIAGNOSIS OF RURAL WAREHOUSE CONDOMINIUMS IN WEST BAY
}

\begin{abstract}
The present work had as purpose to identify the existence and perspectives of Rural Warehouse Condominiums in the West Bahia, as well as the distribution logistics, which is inserted in the new agricultural frontier in the country, MATOPIBA. To achieve this goal, an applied, exploratory, descriptive and qualitative research was conducted through semi-structured interviews. Data analysis was performed using Content Analysis. It was found that local farmers participate in some forms of Associativism, such as Cooperatives and Associations. It was also found possible evidence of the existence of Rural Warehouse Condominium in West Bahia, in addition to Cerealists in the region. Moreover, given the representative local production and storage deficit, there is potential for the implementation of Rural Warehouse Condominiums in the region. Being a relatively new theme, respondents knew little about collective action and its characteristics. In this context, this work has contributed to the dissemination of the theoretical framework and knowledge about Rural Warehouse Condominiums in the region, and opens opportunities for further research on collective action.
\end{abstract}

Keywords: Rural Collective Actions; Logistic; Rural Development.

JEL: Q13. 


\section{INTRODUÇÃO}

O Brasil esta entre os maiores produtores e exportadores de soja do mundo, atingindo recordes de produção a cada safra, com um total de 246,4 milhões de toneladas de grãos na última safra 2018/19. A nova fronteira agrícola, representada pelos estados do Maranhão, Tocantins, Piauí e Bahia, e popularmente conhecida como MATOPIBA (BRAGANÇA, 2018), também se destaca nesse cenário, com 9,11\% da produção brasileira, isto é, 22,45 milhões de toneladas de grãos (CONAB, 2019).

Particularmente o Oeste Baiano é uma das regiões que mais crescem e impulsionam o desenvolvimento da economia do estado, além de ser o maior produtor do Nordeste. Na safra de 2018/19 a Bahia produziu 8,2 milhões de toneladas de grãos, com destaque para os municípios de Luís Eduardo Magalhães, Barreiras e Formosa do Rio Preto (CONAB, 2019; ABAPA, 2019).

Contudo, os investimentos em estruturas necessárias para o armazenamento e transporte adequado não acompanham esse ritmo, falta armazenagem, e muitos produtores enfrentam filas em picos de safras para o carregamento e descarregamento (CAIXETA-FILHO, 2006; OLIVEIRA, 2011; BRANCO et al., 2010; CICOLIN; OLIVEIRA, 2016). Notadamente, evidencia-se a necessidade de investimentos em infraestrutura (MEDINA, 2017).

A devida armazenagem é determinante para o crescimento do país (BRIGATTE; TEIXEIRA, 2011), e, proporciona vantagens, como a conservação do produto e a comercialização estratégica em momento oportuno (NEVES; CONEJERO, 2007; NOGUEIRA JUNIOR; TSUNECHIRO, 2005; MARTINS et al., 2005; FILIPPI, GUARNIERI, 2019).

Para driblar esses gargalos e se manterem competitivos frente aos demais produtores mundiais, uma nova forma de ação coletiva vem ganhando notoriedade no cenário nacional, os Condomínios de Armazéns Rurais (FILIPPI; GUARNIERI, 2018; FILIPPI et al., 2018; FILIPPI, GUARNIERI, 2019; FILIPPI; GUARNIERI, CUNHA, 2019; FILIPPI et al., 2019). Os Condomínios de Armazéns Rurais são ações coletivas rurais Associativistas que viabilizam estruturas de armazenagem em conjunto divididas em cotas. O modelo reduz gargalos logísticos, reduz custos de transporte e armazenagem, e, gera lucro 
ao produtor rural, bem como, vantagens do sistema condominial e da armazenagem (FILIPPI et al., 2019; FILIPPI, GUARNIERI, 2019).

Portanto, o objetivo desse artigo é identificar a existência e perspectivas de Condomínios de Armazéns Rurais no Oeste Baiano, bem como, a logística de distribuição. Para tanto, realizou-se uma pesquisa aplicada, exploratória, descritiva e de abordagem qualitativa, através de entrevista semiestruturada. A análise de dados se deu através da Análise de Conteúdo de Bardin (1977).

\section{OESTE BAIANO E AÇÕES COLETIVAS RURAIS: A ARMAZENAGEM EM FOCO}

O Brasil destaca-se no cenário mundial como um dos maiores produtores e exportadores de grãos, sendo que na safra 2018/19 produziu um total de 246,4 milhões de toneladas. Particularmente no Oeste Baiano, o qual, pertence à nova fronteira agrícola (BRAGANÇA, 2018), composta pelos estados do Maranhão, Tocantins, Piauí e Bahia (MATOPIBA), a produção alcança 22,45 milhões de toneladas de grãos, isto é, 9,11\% da produção nacional (CONAB, 2019).

O Oeste Baiano é umas das regiões mais representativa do Nordeste para o Agronegócio e que mais cresce e impulsiona o desenvolvimento da economia do estado. Na safra 2018/19 a Bahia produziu 8,2 milhões de toneladas de grãos, com destaque para os municípios de Luís Eduardo Magalhães, Barreiras e Formosa do Rio Preto (CONAB, 2019; ABAPA, 2019).

Atualmente um dos problemas logísticos que os produtores enfrentam é com o armazenamento dos seus produtos, e filas em armazéns de terceiros em picos de safra para carregamento e descarregamento. O crescimento do país no cenário competitivo de exportadores nos últimos anos e o aumento da produção não acompanhou o mesmo ritmo da infraestrutura logística, gerando falta de locais adequados para guardar o produto, e consequentemente, a perda de competitividade e de qualidade do mesmo (CAIXETA-FILHO, 2006; OLIVEIRA, 2011; BRANCO et al., 2010; CICOLIN; OLIVEIRA, 2016). 
A armazenagem proporciona algumas vantagens para o produto e para o negócio, como a conservação do produto e a comercialização estratégica em momento oportuno, como por exemplo, em épocas de entressafra quando existe baixo estoque do produto no mercado e melhores preços (NEVES; CONEJERO, 2007; NOGUEIRA JUNIOR; TSUNECHIRO, 2005; MARTINS et al., 2005; FILIPPI, GUARNIERI, 2019). Brigatte e Teixeira (2011) também relatam que a armazenagem é determinante para o crescimento do país. Dessa forma, oferecer um sistema de armazenamento eficiente e eficaz no país é condição para o desenvolvimento rural e do Agronegócio.

Nesse cenário o Associativismo se destaca gerando fortalecimento ao Rural Brasileiro e as dificuldades do campo (DE CARVALHO; RIOS, 2008; SAUSEN; PATIAS; ALLEBRANDT, 2011; BORGES; DOMINGUES, 2017). As Organizações a partir das origens Associativistas permitem maior eficiência, são relevantes no desenvolvimento econômico, social e locais (BORGES; DOMINGUES, 2017; SAUSEN; PATIAS; ALLEBRANDT, 2011), geram desenvolvimento, emprego e renda, e, proporcionam condições favoráveis ao acesso do crédito rural, acesso a novas tecnologias e parcerias institucionais (DE CARVALHO; RIOS, 2008).

Assim, os Condomínios de Armazéns Rurais emergem para superar desafios do campo e manter a competitividade frente aos principais produtores e exportadores de grãos. Os Condomínios de Armazéns Rurais são ações coletivas Associativistas entre pequenos e médios produtores rurais vizinhos que viabilizam estruturas de armazenagem e as dividem em cotas de armazenagem (FILIPPI et al., 2019; FILIPPI, GUARNIERI, 2019; FILIPPI; GUARNIERI, CUNHA, 2019; FILIPPI et al., 2018; FILIPPI; GUARNIERI, 2018).

A nova Organização Rural Brasileira reduz gargalos logísticos, reduz custos de transporte e armazenagem, e, gera lucro ao produtor rural, bem como, vantagens do sistema condominial e da armazenagem (FILIPPI, GUARNIERI, 2019; FILIPPI et al., 2018; FILIPPI et al., 2019). Ela também é viável financeiramente aos pequenos e médios produtores (FILIPPI; GUARNIERI, 2018). 
Atualmente, existe pouca literatura sobre o assunto e pouco conhecimento sobre o modelo, sendo que se sabe da existência de Condomínios de Armazéns Rurais, concentrados na região de Palotina/PR e estado do Rio Grande do Sul (FILIPPI, GUARNIERI, 2019; FILIPPI et al., 2019). Dessa forma, torna-se importante e relevante a difusão do conhecimento sobre o modelo coletivo rural.

\section{MÉTODOS E TÉCNICAS DE PESQUISA}

A presente pesquisa é classificada como aplicada, exploratória, descritiva e qualitativa (SILVA; MENEZES, 2005). Para a coleta de dados realizou entrevista semiestruturada, a qual permite liberdade de condução e adaptações quando necessário, principalmente, quando o objeto de estudo é pouco conhecido (MARCONI; LAKATOS, 2003), juntamente com a análise documental.

A entrevista foi realizada com dois entrevistados de órgãos representativos rurais da região Oeste da Bahia, um governamental e outro privado, os quais tinham experiência e conhecimento sobre o assunto. O roteiro de entrevista foi dividido em três seções: (i) a primeira seção composta de oito itens tinha por objetivo entender as características dos produtores rurais e da região do Oeste da Bahia; (ii) a segunda seção era composta por nove itens, que procuravam entender sobre a logística e a forma de armazenagem da soja no Oeste baiano, bem como os gargalos e o déficit que a região apresenta quanto a essas questões; e, (iii) a terceira seção era composta por oito itens que buscavam compreender a identificação e a caracterização de possíveis Condomínios Rurais no Oeste baiano, além da visão que os entrevistados possuem sobre esse assunto, a sua contribuição para os produtores e região, e, sua contribuição para diminuir os gargalos da armazenagem. Além disso, a elaboração do roteiro de perguntas se baseou na literatura disponível sobre o assunto.

Os dados obtidos foram transcritos e analisados através da Análise de Conteúdo de Bardin (1977). A Análise de Conteúdo permite interpretar falas e comunicações, bem como, elaborar categorias sobre assuntos pouco conhecidos (BARDIN, 1977). Dentre as vantagens da técnica esta a análise da pesquisa como prática local e compreensão das relações em seu tempo e situação (FLICK, 2009; GOLAFSHANI, 
2003). Trabalhos como de Costa, Filippi e Guarnieri (2020) e Carvalho, Filippi e Guarnieri (2020) exemplificam-se estudos de caso.

Posteriormente, a categorização foi posteriori com a elaboração de três categorias: (1) Caracterização do Oeste Baiano e ações coletivas; (2) Logística de Distribuição no Oeste Baiano; e, (3) Percepção sobre os Condomínios de Armazéns Rurais. A próxima seção exibe os Resultados e Discussão. Os resultados são apresentados e discutidos na próxima seção.

\section{RESULTADOS E DISCUSSÃO}

\subsection{Caracterização do Oeste baiano e ações coletivas}

A primeira categoria descreve as características dos produtores rurais do Oeste da Bahia, como também as características da própria região e as ações coletivas locais.

O Oeste da Bahia se caracteriza pela produção majoritária de soja e milho, com 650 produtores, seguido de produção de algodão, com 150 produtores. O entrevistado B (órgão público), relatou que a Secretaria de Agricultura local é responsável pelo fomento e atuação na agricultura familiar, e que os produtores locais de soja possuem estrutura organizacional própria, o que faz com que eles tenham somente algumas parcerias atreladas a questões ambientais, e para poder ter aproximação entre a própria cadeia produtiva do Agronegócio e agricultura familiar local.

Logo, devido ao tamanho da região e da área de cultivo se estabelece um sistema de monocultura onde prevalece uma forma de empreendedorismo no qual existe grande quantidade de terras nas mãos de poucos produtores, o que os torna não dependentes de entidades públicas, como a Secretaria da Agricultura.

Quando questionados sobre a área de cultivo que esses produtores possuem e se são somente produtores de soja, o entrevistado A (órgão privado) informou que em média eles tem uma área de 3 mil hectares, as quais são divididos em produtores soja ou de soja e milho. Além disso, eles cultivam outras culturas após a safra da soja, como feijão, mileto, sorgo. Existem também os produtores que plantam as três culturas ao mesmo tempo, algodão, soja e milho. Já o entrevistado B disse que apesar da soja ser o 
“carro chefe" da região, os produtores não são exclusivamente produtores de soja, mas também de milho e algodão, formando as três principais commodities da região. Alguns produtores ainda cultivam café e trigo, este último ainda em fase de estudo e instalação, porém já existe produção desse insumo na região.

Em relação ao perfil dos produtores da região, o entrevistado A disse que a maioria são grandes produtores no Oeste Baiano, porém há pequenos e médios também, e áreas variando de 300, 3 mil hectares e acima disso. De acordo com o entrevistado A, o grande produtor esta envolvido com o "Agronegócio" e o pequeno produtor mais envolvido com a Agricultura Familiar.

Sobre as ações coletivas locais e Associativismo, o entrevistado A e o entrevistado B disseram que existe sim relações Associativistas na região. Para o entrevistado $\mathrm{B}$, a união dos produtores se dá justamente pela característica do Nordeste em si, dificuldade da região e logísticas, que faz com que os produtores busquem Associações e o Cooperativismo para driblar as problemáticas do local, embora considere que a região ainda seja carente desse sistema.

Ele ainda cita a Associação de Agricultores e Irrigantes da Bahia (AIBA) e a Associação Baiana dos Produtores de Algodão (ABAPA) como exemplos, relatando que quando essas Associações, que vieram da região Sul e Sudeste do país, foram instaladas nessa região, em meados da década de 70 e 80 , apesar da facilidade da terra planas e condições pluviométricas favoráveis, ele afirma que a "coisa" na região era muito difícil devido a um "vazio" que as terras apresentavam e precisava de uma "colonização" das áreas, colonização que só seria possível com essa forma de Associativismo que eles trouxeram de lá.

Além disso, as ações coletivas na região estão envolvidas com recuperação de estradas, preservação ambiental, logística, trabalhista e social. Desenvolvidas não só pelas Associações como também pelos sindicatos do Fundo de Assistência ao Trabalhador Rural (Funrural):

“que está em evidência a questão do Funrural, é uma ação que estão aqui pela associação, estão no sindicato, então é tudo que for de interesse do produtor, é fortalecido pelo associativismo" (Entrevistado A, 2019). 
Ademais, os produtores rurais da região são associados da AIBA. O entrevistado A disse que $90 \%$ dos produtores locais fazem parte dessa associação rural, além dos produtores que possuem as suas próprias associações e dos que participam de Sindicatos Rurais e outras associações. O entrevistado B citou a possibilidade de produtores ligados a ABAPA também. De acordo com Borges; Domingues (2017) e Sausen, Patias e Allebrandt (2011), o Associativismo fortalece o rural brasileiro e auxilia a superar as dificuldades do campo, permitindo mais eficiência nas ações coletivas, e são relevantes para o desenvolvimento econômico, social e local, gerando emprego e renda, e, proporcionam condições favoráveis ao acesso do crédito rural, acesso a novas tecnologias e parcerias institucionais (DE CARVALHO; RIOS, 2008).

Por fim, quanto ao custo de produção de soja e dos demais grãos, o entrevistado A (órgão privado) relatou que a região tende a ser mais suscetível a pragas, o que torna o controle das pragas mais caro para os produtores do Oeste Baiano comparado aos produtores de outras regiões do país. Outra questão que ele apresenta como fator de aumento do custo de produção é a da escolha da logística que deve acompanhar as características do local, pois segundo ele a região possui escoamento predominantemente rodoviário apesar de ter condições de usar os modais, ferroviário e hidroviário, caso houvesse investimentos.

Sabe-se que no país existe o uso excessivo e abusivo de uma única modalidade de transporte, bem como, o pouco uso da intermodalidade. Além disso, de acordo com a literatura, os investimentos em estruturas necessárias para o armazenamento e transporte adequado não acompanham o mesmo ritmo de crescimento da produção brasileira a cada nova safra, falta armazenagem (CAIXETA-FILHO, 2006; OLIVEIRA, 2011), e os produtores rurais enfrentam filas, principalmente em picos de safras, nas operações de carregamento e descarregamento em Armazéns e portos.

Além disso, o entrevistado A afirmou que o escoamento dos grãos da região é realizado em caminhões através das rodovias que ligam o Oeste Baiano até os principais locais de destino, a exemplo dos portos em Salvador e das fazendas de armazenagem. O entrevistado B (órgão público) disse que não possui parâmetro desse custo, pois não tem base de dados sobre o assunto. 
Segundo Bowersox e Closs (2001) a competência operacional se dá através de uma qualidade predefinida de serviço de forma que a logística satisfaça as demandas dos clientes, auxilie na qualidade, e, que se bem implementada pode equilibrar as expectativas de serviços e gastos. Dessa forma, o escoamento eficiente da produção através da escolha adequada da modalidade de transporte, de acordo com suas características operacionais, e considerando o tipo de produto, reduzem custos logísticos e otimizam a distribuição, reduzindo ainda perdas desnecessárias.

\section{LOGÍSTICA DE DISTRIBUIÇÃO NO OESTE BAIANO}

A segunda categoria busca compreender como funciona a logística, distribuição e armazenamento de grãos, principalmente soja na região.

Para armazenar o produto, principalmente soja, o entrevistado A informou que os produtores utilizam duas principais maneiras: (i) Tradings, em que logo após a colheita já depositam os grãos em armazéns particulares de Tradings (empresas particulares comercializadoras); e, (ii) armazéns próprios, que abrange certa porcentagem de produtores possuem, porém o entrevistado afirma que essa segunda maneira é bem deficitária e deve atender a menos da metade da produção.

$\mathrm{O}$ entrevistado $\mathrm{B}$ informou que a região possui silos em condições adequadas, mas talvez não em quantidades suficientes, por isso quando ocorre a colheita de soja e não possui espaço suficiente para a armazenagem, o produto é transportado diretamente para o porto de Aratu/BA e Paranaguá/PR, enquanto boa parte dos grãos, os que permanecem na região, são transportados e armazenados em silos de empresas, como Cargill e Bunge (Figura 1). Informação corrobora com as informações do entrevistado A, que são multinacionais instaladas na região, recebem parte dessa produção e processam. 
Figura 1 - Silo Metálico convencional e Silo Bag no Oeste Baiano.
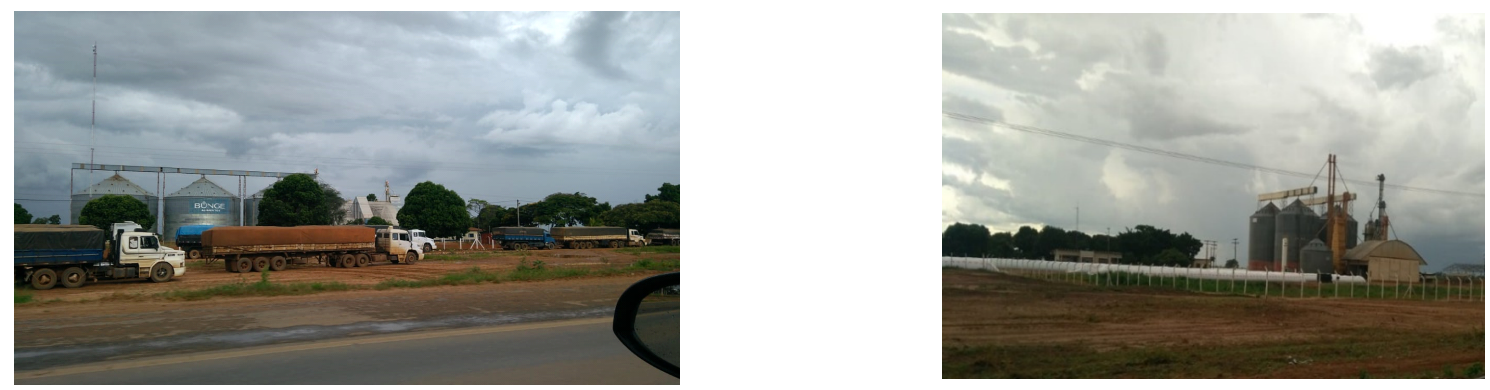

Fonte: Resultados da Pesquisa (2019).

De acordo com a Figura 1, observam-se dois tipos de unidades armazenadoras, uma metálica e outro do tipo bag. O silo metálico é indicado para armazenar grãos após processo de secagem com o intuito de retirar o excesso de umidade, conservar melhor o produto, possui maior capacidade de guarda em menor superfície, e, pode armazenar os grãos por mais tempo, já que possui ventilação e controle de temperatura, além da facilidade para carga e descarga do produto. Já o silo bag é uma estrutura horizontal provisória, contudo oferece autonomia ao produtor que pode estocar a safra em sua própria propriedade rural de forma segura, sendo que o produto ainda continua sendo dele.

Em relação ao mapeamento de déficit de armazenagem e sobre as condições físicas e estruturais adequadas na região, o entrevistado A informou que existe sim um déficit de armazenagem tanto nas Tradings quanto dentro das próprias propriedades. Por isso, usam-se muito os silos bolsa (silos bags), porém, eles só podem ser usados nas colheitas do fim da safra, quando chove menos e a soja está com umidade baixa. Dessa forma, como possuem limite de armazenagem, a exportação tem que ser logo após a colheita, assim a logística de transporte é feita através de caminhões até o porto de Aratu, em Salvador, e depois distribuído de navio para exportação.

Ele salientou a importância da logística não falhar, pois como a armazenagem é deficitária depende desse escoamento para dar espaço a soja ou produto que já está sendo colhida. A fala do entrevistado A corrobora com a visão de Gentil e Martin (2014) que afirmam que um dos maiores problemas atuais que os produtores enfrentam é com a questão do armazenamento de suas commodities, pois o Brasil não é 
um país que estava preparado para enfrentar os gargalos logísticos ocasionados pelo aumento da produção e crescimento das exportações.

Quanto aos principais gargalos logísticos enfrentados pelos produtores da região, o entrevistado A disse eles os problemas logísticos se concentram quando começa a época de colheita, momento que chove e as estradas vicinais ficam em condições precárias, e quando, o produtor não tem armazém próprio já que chuvas dificultam o transporte dos grãos da fazenda para a unidade armazenadora.

Nesse sentido, as Associações locais buscam encontrar soluções para a recuperação de estradas com o intuito de reduzir esse gargalo, para então distribuir a soja para Salvador/BA, distante cerca de $900 \mathrm{~km}$ da local produtivo. Além da dificuldade de escoar os grãos por estradas precárias em época de chuva, existe também a dificuldade do carregamento dos navios, em que o porto de Aratu só conta com um berço para o carregamento, uma vez que o início da exportação também coincide com o período chuvoso em Salvador, e como a carga não pode molhar, carregar os navios em época de chuva é complicado, podendo aumentar as perdas de produto.

Para o entrevistado B o principal gargalo é a questão financeira, como a falta de investimento pelas entidades financeiras locais, além da dificuldade de acesso ao crédito rural para esse fim. Ele disse que a produção de soja da região é bastante expressiva e que por falta desses investimentos acaba ocorrendo uma falta de silos na região.

Vale ressaltar aqui a importância das políticas públicas condizentes com a realidade e necessidades locais de cada região do país, bem como, perfil do produtor rural para acesso ao crédito através das entidades financiadoras, de forma a contribuir com a redução de problemas rurais, e proporcionar o crescimento e desenvolvimento.

Ademais, quanto ao custo de armazenagem, o entrevistado A disse que os valores variam. O custo para transportar soja do oeste baiano para Salvador é alto, de 160 a 180 reais a tonelada, enquanto das fazendas para os armazéns o custo depende do local, se a estrada for ruim o frete tende a aumentar, se estiver em melhores condições o custo tende a ser mais baixo. De qualquer forma, o custo comparado com outras regiões do país segue essa mesma tendência, condições melhores de logística, fretes 
melhores; condições ineficientes de logística, fretes mais caros. Vale lembrar que o frete é um dos principais componentes do custo de transporte e reflete no custo final do produto (BALLOU, 2006; CAIXETA-FILHO, 2006).

Quando questionado sobre alternativas de armazenagem para os produtores locais, o entrevistado A informou que se o produtor não tiver alguma alternativa na própria fazenda e ele não conseguir entregar toda produção na Trading, eles tem a opção de armazenar no silo bolsa, o qual é muito usado principalmente se estiver com pouca umidade na região, caso a soja estiver seca.

Contudo, se estiver chovendo e a soja precisar passar pela secagem, não se recomenda o seu armazenamento nesse tipo de silo, o que acaba gerando filas na entrega e muita espera no descarregamento, pois ela tem que passar pelo secador. Já o entrevistado B disse que tanto a parte municipal quanto a estadual não possuem essa alternativa, porque a CONAB não atua na região com esse tipo de estoque.

De acordo com Brigatte e Teixeira (2011), a armazenagem em condições adequadas é determinante para o crescimento do país. Proporciona ainda vantagens, como a conservação do produto e a comercialização estratégica em momento oportuno (NEVES; CONEJERO, 2007; NOGUEIRA JUNIOR; TSUNECHIRO, 2005; MARTINS et al., 2005; FILIPPI, GUARNIERI, 2019). Assim, os produtores da região que não tem estrutura de armazenagem própria ou por algum motivo as estruturas de terceiros estão lotadas, não poderão usufruir da comercialização estratégica da produção e dependem de terceiros, podendo enfrentar filas em períodos de safras.

Quanto ao destino final da distribuição, o entrevistado A relatou que mais ou menos 50\% são distribuídas para exportação com destino a países da Ásia, principalmente para China, e a outra metade atende o Nordeste, o mercado interno, as granjas do Nordeste em que parte do produto é esmagado nas indústrias da região e vai em forma de farelo, e outra parte in natura. Multinacionais como a Bunge e a Cargill, são exemplos de empresas que esmagam soja na região. Para o entrevistado B o principal destino é exportação e uma parte fica na região com as multinacionais, já que uma parte do grão, no caso soja e milho, serão transformados em ração animal. 
Por fim, sobre a forma de distribuição da produção e qual a modalidade de transporte, o entrevistado A disse que o escoamento é feito somente de modo rodoviário, em caminhões rodotrem de 37 toneladas, já que a ferrovia que seria construída na região ficou apenas na promessa e a hidrovia do São Francisco que era muito utilizada nos anos 90, que levava soja de São Francisco até Petrolina, não está mais navegável.

Quando questionado se a hidrovia não é mais utilizada por conta das condições, ele disse que essa forma de escoamento é viável, se tivesse manutenção e dragagem do leito do rio, porém sem manutenção ela se torna inviável. O entrevistado A também informou que há três ou quatro anos ela ainda era utilizada, com dificuldade, para o transporte de cargas de algodão e que o governo Federal ainda chegou a prometer que faria uma licitação para fazer a dragagem do canal, mas o projeto não foi aprovado e por isso não foi realizado.

Para o entrevistado B ele também disse que o principal modal é o rodoviário, mas afirmou que a região também possui uma ferrovia e está em processo de construção há um bom tempo, que já era pra ter terminado, porém não tem previsão para conclusão. Vale ressaltar que a modalidade ferroviária é mais competitiva para o transporte de longas distâncias e de commodities. Além disso, de acordo com a Confederação Nacional do Transporte (CNT, 2018) as condições das estradas da Bahia estão 37\% em estado regular, $13 \%$ em estado ruim, 5\% em péssimo estado, ou seja, 55\% das estradas estão em condições precárias de escoamento, o que causa a perda de produtos e custos desnecessários.

\section{PERCEPÇÃO SOBRE OS CONDOMÍNIOS DE ARMAZÉNS RURAIS}

A última categoria busca identificar e compreender a percepção do modelo Condomínios Rurais no Oeste baiano, como também perspectivas sobre o modelo na região.

A primeira pergunta foi se os entrevistados já tinham ouvido falar/conheciam os Condomínios de Armazéns Rurais e se saberiam explicar o que é. Segundo o entrevistado A, a região não possui Condomínios de Armazéns Rurais. Ele informou sobre a existência de uma família na região em que são vários irmãos que são produtores de soja e criaram um modelo parecido com Condomínio Rural para 
facilitar as negociações, principalmente em relação a burocracias. Apesar de contar com armazenagem própria, esse modelo não é especificamente para armazenagem e sim para centralizar as negociações em torno de matrículas das fazendas que são da família. Ele ainda complementa que além das Tradings, existem empresas que prestam serviço de armazenagem particular onde armazenam a soja por um tempo e depois o produtor vai buscar ou armazenar mais grãos. Porém esse serviço não é caracterizado como um Condomínio de Armazém Rural (FILIPPI; GUARNIERI, 2018; FILIPPI; GUARNIERI, 2019).

Além disso, o entrevistado A relatou que o que eles tem de mais próximo de um Condomínio de Armazém Rural é o sistema de Cooperativas de armazenagem. Enquanto o entrevistado B disse que particularmente não havia conhecimento e nem "noção do que poderia ser essa, vamos dizer, forma de associativismo" (Entrevistado B, 2019).

Através das informações fornecidas pelo entrevistado A sobre esse modelo rural criado pelos irmãos, foi possível entrar em contato por telefone com um dos sócios. Segundo informações, a família deixou a Região Sul do País na década de 80, mais precisamente o Rio Grande do Sul, para morar no Oeste da Bahia e então iniciaram e estabeleceram suas atividades agrícolas em Barreiras. O modelo é de grupos familiares que trabalham em um grupo agrícola e tem por objetivo viabilizar a estrutura de armazenagem no Oeste Baiano e conta com mais ou menos 8 produtores, os irmãos, que trabalham na parte burocrática desse modelo.

Devido a região possuir déficit relativamente alto no que tange o armazenamento dos grãos, esses produtores começaram a investir em estruturas de armazenagem, ou seja, eles possuem sua própria estrutura para armazenar os grãos que produzem. Os silos ficam em uma região entre Barreiras e Luís Eduardo Magalhães e se assemelham muito aos Condomínios de Armazéns Rurais que estão localizados no Sul do país, e principalmente na região de Palotina/PR (FILIPPI; GUARNIERI, 2018; FILIPPI; GUARNIERI, 2019). 
No entanto, embora muito parecidos, não é possível afirmar que essa estrutura seja um Condomínio de Armazenagem Rural sem antes fazer uma visitação ou estudo in loco para entender melhor esse modelo. Então o que se pode afirmar é que aparentemente essa seja uma organização similar a um Condomínio de Armazenagem Rural.

Sobre ter conhecimento sobre o modelo de Condomínios de Armazéns Rurais em outras regiões do país, os entrevistados disseram que não sabiam.

Foi questionado aos entrevistados se eles consideravam que o modelo de Condomínios de Armazéns Rurais seria vantajoso e oportuno aos produtores locais e quais as vantagens que eles trariam caso participassem. Para o entrevistado A esse modelo pode ser uma solução viável e interessante para regiões de pequenos produtores que não possuem condições de cada um ter a sua própria armazenagem. Enquanto o entrevistado B afirma que acha "louvável" toda forma de Associativismo, pois o produtor individual não consegue fazer nada sozinho, e a partir do momento que os produtores realizam essa estruturação eles podem encontrar uma alternativa para resolver seus problemas.

Segundo Filippi e Guarnieri (2018 e 2019), os Condomínios de Armazéns Rurais proporcionam inúmeras vantagens logísticas e de natureza econômica para os produtores que optam por essa forma de ação coletiva. Entre elas, destacam-se maior agregação de valor ao produto, redução de custos, aumento do lucro, maior rentabilidade sobre produção, eliminação do intermediário na comercialização da produção, comercialização estratégica e eliminação de filas.

Quanto a contribuição logística e para armazenagem dos Condomínios de Armazéns Rurais para região, o entrevistado A disse que os Condomínios podem ser sim algo novo que pode auxiliar as regiões que são deficitárias, pois muitas vezes uma pessoa sozinha não possui condições de ter um local adequado para o armazenamento da soja e de ter o seu próprio armazém.

Em relação ao custo de implantação dos Condomínios de Armazéns Rurais, os entrevistados não souberam dizer sobre sua viabilidade e nem qual o custo do modelo. De acordo com Filippi e Guarnieri (2018) o modelo é viável financeiramente. 
Quando questionados se existe incentivos financeiros governamentais para os produtores rurais, o entrevistado A respondeu que há linhas de financiamento para armazenagem. Porém a questão da garantia muitas vezes barra o financiamento, uma vez que já existe um financiamento para a produção e normalmente a terra do produtor já está penhorada para a produção agrícola. Logo, alguns produtores conseguem o financiamento para armazenagem, porém a maioria não, pois não possuem outra área que possam "penhorar" para conseguir também o financiamento de armazenagem.

O entrevistado complementou que além do problema de não existir a garantia e isso travar o aumento da armazenagem, possui o problema da disponibilidade de energia elétrica, uma vez que o armazenamento consome muita energia e muitas regiões têm déficit ou falta de fornecimento de energia, a possibilidade que existe é a de utilizar o diesel, porém seria uma forma que ficaria cara. Ele explica e cita como exemplo o município de Formosa do Rio Preto, que é o maior município da Bahia, praticamente não tem energia, e que na maior parte das fazendas os armazéns que o município possui usam a energia do diesel, o que torna o custo deles mais oneroso.

Para o entrevistado B, a nível municipal existe um programa, inclusive dentro da Secretaria, chamado "Agro Forte". O programa segundo o entrevistado é utilizado para a melhoria das estradas vicinais e pontes de acesso que dão acesso as fazendas, pois essas melhorias auxiliam no transporte dos insumos, uma vez que as estradas de acesso tendem a ser precárias, o que as tornam gargalos tanto do município, como de qualquer região produtora do país.

Por fim, a última pergunta feita aos entrevistados foi se eles conseguiam pensar nos Condomínios de Armazéns Rurais como uma maneira eficiente e eficaz para reduzir os gargalos logísticos. O entrevistado A disse que acha eficiente sim, porque "soluções em conjunto são melhores do que as tomadas sozinhas", e exemplifica com um caso da região de Baianópolis. A região conta com aproximadamente 50 produtores, todos abaixo de 1000 hectares, a maioria deve ter 500 hectares, para ele esse é um exemplo de que não compensa cada um ter o seu armazém e como eles também não possuem nenhuma Trading e nenhuma unidade de recebimento perto, esse é um caso que para ele com certeza daria certo, pois se fizerem a conta individual não compensa, mas todos juntos seria viável. 


\section{CONSIDERAÇÕES FINAIS}

O objetivo geral deste artigo foi identificar a existência e perspectivas de Condomínios de Armazéns Rurais no Oeste Baiano, bem como, a logística de distribuição na região.

O novo modelo de ação coletiva rural ainda é novo e pouco conhecido no país (FILIPPI; GUARNIERI, 2018; FILIPPI; GUARNIERI, 2019). Especificamente no oeste baiano, não foi constatado Condomínios de Armazéns através dessa pesquisa. Contudo, existe potencial para implantação do modelo de ação coletiva rural na região, principalmente para driblar problemas logísticos enfrentados pelos produtores locais, como o déficit de armazenagem e filas, e assim, aumentar a competitividade local e reduzir perdas.

Quanto a logística de distribuição, a região possui silos metálicos e silos bags em condições adequadas. Contudo, persiste o déficit de armazenagem no oeste baiano para guardar a produção de grãos, principalmente em picos de safras, tanto para as tradings, quanto para os produtores rurais. Dessa forma, quando os armazéns estão lotados, procede-se com o transporte rodoviário, e posterior exportação do produto aos portos de Aratu/BA ou Paranaguá/PR.

Além disso, o fato dos produtores precisarem utilizar as Tradings ou armazéns de terceiros eleva o custo deles. Dessa forma, investir em formas de armazenamento coletivo se mostra como um modo eficiente e eficaz para reduzir custos, e, auxiliar os pequenos e médios produtores na viabilização de estruturas próprias de armazenagem.

Ainda, foi constatado a importância da logística de distribuição não falhar na região, visto o déficit de armazenagem que existe, e necessidade de espaço ao produto que esta sendo colhido no campo. Ademais, outros gargalos logísticos exemplificam-se na região, como estradas em condições precárias e falta de armazém próprio do produtor rural. Condições estas que favorecem a criação de novos armazéns ou diluição do custo de armazenagem dos produtores por meio de ações coletivas, como os Condomínios de Armazéns. 
Por fim, quantos as modalidades de transporte, predomina o uso do modal rodoviário no oeste baiano. O modal ferroviário, mesmo sendo mais adequado e competitivo ao transporte de commodity, não esta em uso, pois a ferrovia que seria viabilizada na região ainda não foi construída. Já a hidrovia do São Francisco até Petrolina, que também é mais competitiva em relação ao modal rodoviário, não está navegável devido a falta de manutenção e dragagem do leito do rio. Dessa forma, o escoamento da produção de grãos na região se dá principalmente pelo modal rodoviário, consequentemente gerando maior custo logístico para o produto e não sendo a modalidade mais eficaz para esse tipo de produto.

Como sugestão de estudos futuros, indica-se pesquisas diretas com os próprios produtores rurais da região, survey ou pesquisas quantitativas para alcançar maior número de entrevistados, principalmente produtores. Sugere-se também, compreender a formação citada por um dos entrevistados desse estudo, o qual assemelha-se ao modelo de Condomínios de Armazéns Rurais, com o intuito de compreender in loco como seria o modelo.

Ademais, as contribuições dessa pesquisa, por ser um tema relativamente novo, os entrevistados pouco sabiam da ação coletiva e de suas características. Nesse sentido, esse trabalho contribuiu para a difusão do arcabouço teórico e de conhecimento sobre os Condomínios de Armazéns Rurais na região, e abre oportunidades de novas pesquisas sobre a ação coletiva. Dentre as limitações do estudo, a pesquisa limita-se ao conjunto de dados fornecidos pelos entrevistados, características regionais e metodologia aplicada.

\section{AGRADECIMENTOS}

FAP/DF - Fundação de Apoio à Pesquisa do Distrito Federação. UnB - Universidade de Brasília. 


\section{REFERÊNCIAS}

ABAPA - ASSOCIAÇÃO BAIANA DE PRODUTORES DE ALGODÃO (2019) "Região Oeste concentra mais de um terço de toda riqueza agrícola da Bahia". Disponível em: http://abapa.com.br/mais-noticias/regiao-oeste-concentra-mais-de-um-terco-de-toda-riqueza-agricola-dabahial. Acesso em junho de 2019.

BALLOU, R.H. Gerenciamento da Cadeia de Suprimentos. Logística Empresarial. 5.ed. Porto Alegre: Bookman, 2006. 616p.

BARDIN, L. Análise de Conteúdo. Lisboa: Edições 70, 1977. 225p.

BORGES, G.; DOMINGUES, C. Estratégias de Crescimento de Cooperativas Agrícolas e Agropecuárias: Estudo de Casos Comparados da Região do Triângulo Mineiro/MG e dos Campos Gerais/PR. Organizações Rurais \& Agroindustriais, v. 19, n. 1, 10 jul. 2017.

BOWERSOX, D.J.; CLOSS, D.J. Logística empresarial: o processo de integração da cadeia de suprimento. 1. ed. São Paulo: Atlas, 2001.

BRAGANCA, A. The Economic Consequences of the Agricultural Expansion in Matopiba. Revista Brasileira de Economia, Rio de Janeiro, v. 72, n. 2, p. 161-185, 2018.

BRANCO, J.E.H. et al. Desafios para o desenvolvimento da multimodalidade no transporte das safras agrícolas pelo corredor Centro-Oeste sob a ótica dos agentes envolvidos. Revista de Estudos Sociais, v. 12, n. 23, p. 134-161, 2011.

BRIGATTE, H.; TEIXEIRA, E. C. Determinantes de longo prazo do produto e da Produtividade Total dos Fatores da agropecuária brasileira no período 1974-2005. Revista de Economia e Sociologia Rural, v.49, n.4, p 815-836, 2011.

CAIXETA-FILHO, J.V. A logística do escoamento da safra brasileira. Piracicaba: CEPEA/USP, 2006.

CARVALHO, V.S.; FILIPPI, A.C.G.; GUARNIERI, P. Diagnóstico de ações coletivas rurais no Distrito Federal: um estudo logístico. Gestão \& Regionalidade, 2020.

CICOLIN, L.O.M.; OLIVEIRA, A.L.R. Avaliação de desempenho do processo logístico de exportação do milho brasileiro: uma aplicação da análise envoltória de dados - DEA. Journal of Transport Literature, v. 10, n. 3, p. 30-34, 2016. 
COMPANHIA NACIONAL DE ABASTECIMENTO - CONAB. Séries históricas. Disponível em: https://www.conab.gov.br. Acesso em novembro de 2019.

COSTA, L.M.; FILIPPI, A.C.G.; GUARNIERI, P. Sistemas de gerenciamento de armazéns no Agronegócio e em condomínios de armazéns rurais no Distrito Federal. Informe Gepec, 2020.

DE CARVALHO, D.; RIOS, G. Participação, Viabilidade E Sustentabilidade: Dimensões De Desenvolvimento Local Numa Associação De Produtores Rurais. Organizações Rurais \& Agroindustriais, v. 9, n. 3, 6 abr. 2011.

FILIPPI, A.C.G.; GUARNIERI, P.; CARVALHO, J. M.; REIS, S.A.; CUNHA, C.A. New configurations in Brazilian agribusiness: rural warehouse condominiums. Journal of Agribusiness in Developing and Emerging Economies, v. 10, p. 41-63, 2019.

FILIPPI, A. C. G.; GUARNIERI, P. Novas formas de organização rural: os Condomínios de Armazéns Rurais. Revista de economia e sociologia rural, v. 57, p. 270-287, 2019.

FILIPPI, A. C. G.; GUARNIERI, P.; CUNHA, C. A. Condomínios Rurais: revisão sistemática da literatura internacional. ESTUDOS SOCIEDADE E AGRICULTURA (UFRRJ), v. 27, p. 525-546, 2019.

FILIPPI, A. C. G.; GUARNIERI, P.; SOUZA, C. B. ; CARVALHO, J. M. ; CRUZ, J. E. Análise Das Forças, Fraquezas, Oportunidades e Ameaças Para Os Condomínios De Armazéns Rurais. Informe Gepec, v. 22, p. 43-61, 2018.

FILIPPI, A. C. G.; GUARNIERI, P. Análise Da Viabilidade Econômico-Financeira De Condomínios De Armazéns Rurais: Um Estudo Multicaso. Custos e Agronegocio On Line, v. 14, p. 373-408, 2018.

FILIPPI, A.C.G. Caracterização e análise da viabilidade de Condomínios de Armazéns Rurais: um estudo Multicaso. 2017, 204 f. Dissertação. (Mestrado em Agronegócio) - Faculdade de Agronomia e Medicina Veterinária, Universidade de Brasília, Brasília, 2017.

FLICK, U. Uma introdução à pesquisa qualitativa. 2.ed. Ed. Artmed. Porto Alegre. 2009.

GENTIL, L.V.; MARTIN, S. Armazenagem da produção: É viável para o produtor rural? Revista Agroanalysis. Mercado e Negócios. p. 28-29. Maio de 2014.

GOLAFSHANI, N. Understanding reliability and validity in qualitative research. The qualitative report, v. 8, n. 4, p. 597-606, 2003. 
LAKATOS, E.M.; MARCONI, M.A. Fundamentos de metodologia científica. São Paulo: Atlas, 2003.

MARTINS, R. S.; REBECHI, D.; PRATI, C. A.; CONTE, H. Decisões estratégicas na logística do agronegócio: compensação de custos transporte-armazenagem para a soja no Estado do Paraná. Revista de Administração Contemporânea, v.9, n.1, p 53-78, 2005.

MEDINA, G. Dinâmicas internacionais do agronegócio e implicações para a política agrícola brasileira. Revista de Estudos Sociais, v. 19, n. 38, p. 3-12, 2017.

NEVES, M. F.; CONEJERO, M. A. Sistema agroindustrial da cana: cenários e agenda estratégica. Economia Aplicada, v.11, n.4, p 587-604, 2007.

NOGUEIRA JUNIOR, S.; TSUNECHIRO, A.Produção agrícola e infra-estrutura de armazenagem no Brasil. Informações Econômicas, v.35, n.2, p 8-18, 2005.

OLIVEIRA, A.L.R. A logística agroindustrial frente aos mercados diferenciados: principais implicações para a cadeia da soja. Informações Econômicas, v.41, n.6, p 17-34, 2011.

SAUSEN, J.O.; PATIAS, I.A.; ALLEBRANDT, S.L. Desenvolvimento local e estratégia de pequenos empreendimentos agroindustriais - a lógica da cooperação e do associativismo: o Pacto Fonte Nova. Cadernos EBAPE. BR, Rio de Janeiro, v. 9, n. 3, p. 868-894.

SILVA, E.L.; MENEZES, E.M. Metodologia da pesquisa e elaboração de dissertação. 2005. 